\title{
Effect of Preinfarction Angina Pectoris on Myocardial Blush Grade After Reperfusion in First Anterior Wall Acute Myocardial Infarction
}

\author{
Akira Tamura, MD; Kazuhiro Shinozaki, MD; Toru Watanabe, MD; \\ Toru Nakaishi, MD; Kimiaki Nagase, MD; Jun-ichi Kadota, MD
}

\begin{abstract}
Background The aim of the present study was to clarify the effect of preinfarction angina pectoris (PIA) on myocardial blush grade (MBG), a simple marker of myocardial tissue-level reperfusion, in acute myocardial infarction (AMI).

Methods and Results One hundred forty-two patients with first anterior wall AMI who were admitted within $6 \mathrm{~h}$ after onset of symptoms were examined. PIA was defined as typical chest pain within $48 \mathrm{~h}$ before onset of symptoms. MBG was evaluated by coronary angiography after reperfusion. Patients with MBG 2 or $3(n=103)$ had a higher frequency of PIA and a lower frequency of diabetes mellitus than those with MBG 0 or $1(n=39)$ ( $57 \%$ vs $28 \%, \mathrm{p}=0.004$, and $23 \%$ vs $44 \%, \mathrm{p}=0.03$, respectively). The former had a lower peak creatine kinase level and a greater left ventricular ejection fraction at predischarge than the latter $(3,652 \pm 2,440$ vs $5,507 \pm$ $3,058 \mathrm{IU} / \mathrm{L}, \mathrm{p}=0.0002$, and $57 \pm 12 \%$ vs $45 \pm 11 \%, \mathrm{p}<0.0001$, respectively). Multivariate logistic regression analysis showed that PIA $(\mathrm{p}=0.004)$ and diabetes mellitus $(\mathrm{p}=0.03)$ were independently associated with MBG 2 or 3 after reperfusion.
\end{abstract}

Conclusions PIA has beneficial effects on myocardial tissue-level reperfusion evaluated by MBG in first anterior wall AMI. (Circ J 2006; 70: 698-702)

Key Words: Acute myocardial infarction; Myocardial blush grade; Preinfarction angina pectoris

$\mathbf{T}$ he presence of preinfarction angina pectoris (PIA) has been shown to have beneficial effects on left ventricular (LV) function and prognosis after acute myocardial infarction (AMI) $!^{-7}$ Recently, myocardial blush grade (MBG) has been shown to be a simple and useful marker of myocardial tissue-level reperfusion in AMI-11 Because the effect of PIA on MBG has not yet been investigated, we conducted the present study.

\section{Methods}

\section{Study Patients}

We examined 142 consecutive patients (115 men, 27 women, mean age $61 \pm 11$ years) with first anterior wall AMI who were admitted within $6 \mathrm{~h}$ after onset of symptoms and who met the following criteria: (1) typical chest pain lasting $\geq 20 \mathrm{~min}$; (2) ST-segment elevation $\geq 0.2 \mathrm{mV}$ in $\geq 2$ adjacent precordial leads on the admission electrocardiogram; (3) an increase in the serum creatine kinase (CK) level more than twice the normal value; (4) no other heart or lung disease; (5) emergency coronary angiography and coronary angiography and left ventriculography performed at predischarge; and (6) adequate assessment of MBG after reperfusion. Informed consent for revascularization therapy and follow-up catheterization was given by all patients.

(Received May 12, 2005; revised manuscript received March 16, 2006; accepted March 28, 2006)

Second Department of Internal Medicine, Faculty of Medicine, Oita University, Oita, Japan

Mailing address: Akira Tamura, MD, Second Department of Internal Medicine, Oita University, Hasama, Oita 879-5593, Japan. E-mail: akira@med.oita-u.ac.jp
PIA was defined as typical chest pain within $48 \mathrm{~h}$ before onset of AMI. Diabetes mellitus (DM) was considered present if this diagnosis and treatment, including diet, drugs, or insulin, had been given to the patient or if an abnormal oral glucose tolerance test or hemoglobinA1c $\geq 6.5 \%$ was found after admission.

\section{Cardiac Catheterization}

Emergency coronary arteriography was performed using the Judkins or Amplatz technique. Multiple projections were recorded to ensure optimal visualization of the coronary vessels. The coronary flow in the infarct-related artery was graded according to the classification used in the Thrombolysis In Myocardial Infarction (TIMI) trial!2 Proximal left anterior descending coronary artery (LAD) occlusion was defined as an occlusion of the artery proximal to its first septal branch. The grade of collateral filling in the LAD was determined according to the criteria of Rentrop et al!3 A collateral circulation with a grade of 2 or 3 was defined as "good". After angiographic confirmation of total or subtotal occlusion of the LAD, primary coronary angioplasty was performed. If an optimal result (residual stenosis $<50 \%$ without severe dissection) could not be obtained by balloon coronary angioplasty, coronary stenting was performed $(n=59)$. Successful reperfusion was defined as the establishment of TIMI grade 3 flow in the infarct-related artery on the final coronary arteriogram. MBG was evaluated as follows ${ }^{8}$ on the final left coronary angiogram in the lateral view after reperfusion: $0=$ no myocardial blush or contrast density; $1=$ minimal myocardial blush or contrast density; $2=$ moderate myocardial blush or contrast density, but less than that obtained during angiography of the con- 
Table 1 Clinical and Angiographic Characteristics of the Study Patients

\begin{tabular}{|c|c|c|c|}
\hline & \multicolumn{2}{|c|}{$M G B$} & \multirow{2}{*}{$p$ value } \\
\hline & 2 or $3(n=103)$ & 0 or $1(n=39)$ & \\
\hline Age (years) & $61 \pm 11$ & $61 \pm 10$ & $N S$ \\
\hline Men & $83(81 \%)$ & $32(82 \%)$ & $N S$ \\
\hline Time to admission ( $\mathrm{min}$ ) & $135 \pm 74$ & $144 \pm 70$ & NS \\
\hline PIA & $59(57 \%)$ & $11(28 \%)$ & 0.004 \\
\hline Hypertension & $56(54 \%)$ & $25(64 \%)$ & $N S$ \\
\hline Diabetes mellitus & $24(23 \%)$ & $17(44 \%)$ & 0.03 \\
\hline Smoking & $69(67 \%)$ & $28(72 \%)$ & $N S$ \\
\hline \multicolumn{4}{|l|}{ Emergency coronary angiography } \\
\hline TIMI flow 3 & $7(7 \%)$ & $1(3 \%)$ & NS \\
\hline Good collaterals & $39(38 \%)$ & $9(23 \%)$ & NS \\
\hline Multivessel disease & $35(34 \%)$ & $16(41 \%)$ & $N S$ \\
\hline Proximal LAD occlusion & $66(64 \%)$ & $24(62 \%)$ & NS \\
\hline \multicolumn{4}{|l|}{ Reperfusion therapy } \\
\hline Balloon angioplasty & $96(93 \%)$ & $36(92 \%)$ & NS \\
\hline Stenting & $42(41 \%)$ & $17(44 \%)$ & NS \\
\hline TIMI flow 3 on the final coronary angiogram & $101(98 \%)$ & $28(72 \%)$ & $<0.0001$ \\
\hline Peak CK level (IU/L) & $3,652 \pm 2,440$ & $5,507 \pm 3,058$ & 0.0002 \\
\hline TIMI flow 3 at predischarge & $98(95 \%)$ & $36(92 \%)$ & $N S$ \\
\hline LVEF at predischarge $(\%)$ & $57 \pm 12$ & $45 \pm 11$ & $<0.0001$ \\
\hline Calcium antagonist & $31(30 \%)$ & $13(33 \%)$ & $N S$ \\
\hline$\beta$-blocker & $18(17 \%)$ & $6(15 \%)$ & $N S$ \\
\hline$A C E I$ or $A R B$ & $70(68 \%)$ & $28(72 \%)$ & NS \\
\hline
\end{tabular}

Data are mean \pm SD or number $(\%)$.

MBG, myocardial blush grade; PIA, preinfarction angina pectoris; TIMI, Thrombolysis In Myocardial Infarction; LAD, left anterior descending artery; $C K$, creatine kinase; $L V E F$, left ventricular ejection fraction; ACEI, angiotensin-converting enzyme inhibitor; $A R B$, angiotensin II type 1 receptor antagonist.

Table 2 Associations of PIA With Clinical and Angiographic Characteristics

\begin{tabular}{|c|c|c|c|}
\hline & $P I A(+)(n=70)$ & $P I A(-)(n=72)$ & $p$ value \\
\hline Age (years) & $61 \pm 12$ & $61 \pm 10$ & $N S$ \\
\hline Men & $54(77 \%)$ & $61(85 \%)$ & $N S$ \\
\hline Time to admission (min) & $134 \pm 70$ & $141 \pm 76$ & $N S$ \\
\hline Hypertension & $42(60 \%)$ & $39(54 \%)$ & NS \\
\hline Diabetes mellitus & $21(30 \%)$ & $20(28 \%)$ & NS \\
\hline Smoking & $45(64 \%)$ & $52(72 \%)$ & NS \\
\hline \multicolumn{4}{|l|}{ Emergency coronary angiography } \\
\hline TIMI flow 3 & $4(6 \%)$ & $4(6 \%)$ & NS \\
\hline Good collaterals & $29(41 \%)$ & $19(26 \%)$ & $N S$ \\
\hline Multivessel disease & $24(34 \%)$ & $27(38 \%)$ & $N S$ \\
\hline Proximal LAD occlusion & $45(64 \%)$ & $45(63 \%)$ & $N S$ \\
\hline \multicolumn{4}{|l|}{ Reperfusion therapy } \\
\hline Balloon angioplasty & $64(91 \%)$ & $68(94 \%)$ & NS \\
\hline Stenting & $31(44 \%)$ & $28(39 \%)$ & NS \\
\hline TIMI flow 3 on the final coronary angiogram & $66(94 \%)$ & $63(88 \%)$ & $N S$ \\
\hline$M B G$ & $2.0 \pm 0.6$ & $1.7 \pm 0.8$ & 0.02 \\
\hline Peak $C K(I U / L)$ & $3,280 \pm 2,107$ & $5,020 \pm 3,017$ & 0.0001 \\
\hline TIMI flow 3 at predischarge & $68(97 \%)$ & $66(92 \%)$ & $N S$ \\
\hline LVEF at predischarge $(\%)$ & $59 \pm 11$ & $49 \pm 13$ & $<0.0001$ \\
\hline Calcium antagonist & $23(33 \%)$ & $21(29 \%)$ & NS \\
\hline$\beta$-blocker & $16(23 \%)$ & $8(11 \%)$ & NS \\
\hline$A C E I$ or $A R B$ & $50(71 \%)$ & $48(67 \%)$ & NS \\
\hline
\end{tabular}

Data are mean \pm SD or number $(\%)$.

See Table 1 for abbreviations.

tralateral or ipsilateral non-infarct-related coronary artery; and $3=$ normal myocardial blush or contrast density, comparable to that obtained during angiography of a contralateral or ipsilateral noninfarct-related coronary artery. When myocardial blush persisted, this finding was graded as 0 . MBG 2 or 3 was defined as good myocardial tissue-level perfusion. Reproducibility of the MBG was evaluated by 2 observers viewing 20 samples of the coronary angiograms. Intra- and interobserver agreement was 95\% and 90\%, respectively. Coronary arteriography and left ventriculog- raphy were repeated at predischarge. Left ventriculograms performed in the 30 degree right anterior oblique projection were analyzed for LV ejection fraction (LVEF) by an experienced cardiologist who was unaware of the patients' data. LV end-diastolic and end-systolic volumes were calculated by the area-length method. ${ }^{14}$

\section{Measurements of Serum CK Levels}

Venous blood samples for determination of the peak CK level were obtained every $3 \mathrm{~h}$ during the first $24 \mathrm{~h}$ and once 
Table 3 Logistic Regression Analysis to Determine Factors Related to MBG 2 or 3

\begin{tabular}{|c|c|c|c|c|}
\hline \multirow{2}{*}{ Variables } & \multicolumn{2}{|c|}{ Univariate analysis } & \multicolumn{2}{|c|}{ Multivariate analysis } \\
\hline & Chi-square & $p$ value & Chi-square & $p$ value \\
\hline Age (years) & 0.02 & 0.88 & & \\
\hline Men & 1.31 & 0.25 & & \\
\hline Time to admission ( $\mathrm{min}$ ) & 0.45 & 0.5 & & \\
\hline PIA & 7.62 & 0.006 & 8.19 & 0.004 \\
\hline Hypertension & 1.81 & 0.18 & 1.29 & 0.26 \\
\hline Diabetes mellitus & 5.5 & 0.02 & 5.02 & 0.03 \\
\hline Smoking & 0.07 & 0.8 & & \\
\hline Initial TIMI flow grade & 1.08 & 0.3 & & \\
\hline Proximal LAD occlusion & 0.004 & 0.95 & & \\
\hline Good collaterals & 1.94 & 0.16 & 0.55 & 0.46 \\
\hline Multivessel disease & 0.61 & 0.44 & & \\
\hline Use of stent & 0.09 & 0.76 & & \\
\hline
\end{tabular}

See Table 1 for abbreviations.

daily from the second day until reaching a normal value.

\section{Statistical Analysis}

Data are expressed as mean $\pm \mathrm{SD}$. Continuous variables were analyzed by the unpaired t-test or Mann-Whitney Utest. Univariate and multivariate logistic regression analysis was performed to determine independent factors of MBG 2 or 3 after reperfusion. The variables used for univariate analysis were age, gender, coronary risk factors, PIA, time elapsed from the onset of symptoms to admission, initial TIMI flow grade, good collateral circulation to the LAD, multivessel disease, proximal LAD occlusion, and use of coronary stent. Multivariate logistic regression analysis was performed using variables that showed $p<0.2$ in univariate regression analysis. A p-value $<0.05$ was considered statistically significant.

\section{Results}

Table 1 shows the clinical and angiographic characteristics of the study patients. Distal protection devices were not used in any of them. Patients with MBG 2 or $3(n=103)$ had a higher frequency of PIA and a lower frequency of DM than those with MBG 0 or $1(\mathrm{n}=39)(57 \%$ vs $28 \%, \mathrm{p}=0.004$, and $23 \%$ vs $44 \%, \mathrm{p}=0.03$, respectively). The former had a higher incidence of TIMI flow 3 after reperfusion, a lower peak CK level, and a greater LVEF at predischarge than the latter $(98 \%$ vs $72 \%, p<0.0001 ; 3,652 \pm 2,440$ vs $5,507 \pm$ $3,058 \mathrm{IU} / \mathrm{L}, \mathrm{p}=0.0002$, and $57 \pm 12 \%$ vs $45 \pm 11 \%, \mathrm{p}<0.0001$, respectively). Patients with PIA $(n=70)$ had a greater $M B G$, a lower peak CK level, and a greater LVEF at predischarge than those without it $(\mathrm{n}=72)(2.0 \pm 0.6$ vs $1.7 \pm 0.8, \mathrm{p}=0.02$, $3,280 \pm 2,107$ vs $5,020 \pm 3,017 \mathrm{IU} / \mathrm{L}, \mathrm{p}=0.0001,59 \pm 11$ vs $49 \pm 13 \%, \mathrm{p}<0.0001$, respectively) (Table 2 ).

Table 3 shows the results of univariate and multivariate logistic regression analysis performed to determine independent factors of MBG 2 or 3 after reperfusion. Variables with a value of $p<0.2$ on univariate regression analysis (PIA, DM, hypertension, and good collateral circulation) were used for the multivariate logistic regression analysis, which showed that PIA $(\mathrm{p}=0.004)$ and DM $(\mathrm{p}=0.03)$ were independently associated with MBG 2 or 3 after reperfusion.

\section{Discussion}

The present study results indicate that PIA and DM are associated with MBG 2 or 3 after reperfusion in first anterior wall AMI. As MBG is a simple and useful marker of myocardial tissue-level reperfusion in AMI ${ }^{8-11}$ the results indicate that PIA has protective effects against myocardial tissue-level damage in AMI. The beneficial effects of PIA can be attributed to a reduction in infarct size through myocardial ischemic preconditioning, 1,2,15 PIA could also protect from coronary microvascular damage after reperfusion through microvascular ischemic preconditioning! 16 Ischemia/reperfusion generates reactive oxygen species $(\mathrm{ROS}){ }_{1}^{17}$ which induce impaired endothelium-dependent relaxation and platelet aggregation in arterioles, resulting in vasospasm and thrombosis ${ }^{8,19}$ Capillary endothelial cell swelling, leukocyte-capillary plugging, and leukocytedependent edema after reperfusion lead to capillary noreflow?-24 In postcapillary venules, ROS promotes the production of chemotactic mediators and the expression of adhesion molecules on the surface of leukocytes and endothelial cells, contributing to endothelial barrier disruption and leukocyte adhesion?5,26 These changes after reperfusion lead to microvascular damage. Experimental studies have shown that ischemic preconditioning induces the development of protected phenotypes in endothelial cells lining arterioles, capillaries, and venules ${ }^{18,27-32}$ As a consequence of ischemic preconditioning, vasospasm and thrombosis are less likely to develop in arterioles, capillary perfusion deficits are reduced, and the inflammatory responses in the postcapillary venules are prevented. Thus, ischemic preconditioning could contribute to high MBG at risk area in AMI patients with PIA.

Previous studies have demonstrated that DM is associated with an adverse outcome after AMI ${ }^{33,34}$ Angeja et al ${ }^{35}$ reported that despite an equal rate of TIMI 3 flow after thrombolytic therapy and adjunctive/rescue percutaneous coronary intervention (PCI), diabetic patients had a lower incidence of complete ST-segment resolution after revascularization therapy than nondiabetic patients, suggesting that impaired microvascular flow is greater in the former than in the latter. Our evaluation by MBG provided additional information that the presence of DM affects myocardial tissue-level perfusion in patients with AMI. This unfavorable effect of DM on myocardial tissue-level perfusion may contribute at least in part to the poorer outcomes observed in diabetic patients with AMI 33,34 The exact mechanisms for impaired myocardial tissue-level perfusion after reperfusion in diabetic patients with AMI are unclear, but several have been proposed. First, preexisting impaired endothelium- 
dependent vasodilation, ${ }^{36-38}$ preexisting impaired autoregulatory response of microvessels to increased myocardial demands $\mathrm{s}^{39,40}$ and preexisting structural changes in the coronary microvasculature ${ }^{41}$ could been involved in the poor MBG after reperfusion in patients with DM. Second, hyperglycemia itself could enhance micovascular damage after reperfusion by the generation of ROS via multiple pathways. ${ }^{4}$

\section{Study Limitations}

First, our study sample was relatively small. Second, we examined only selected patients with anterior wall AMI. Therefore, our results might not be applicable to all patients with anterior wall AMI or those with other types of AMI. Third, because we did not record the electrocardiogram at 60 min after reperfusion in all the patients, we could not evaluate the relationship between PIA with ST-segment resolution, another marker of myocardial tissue-level reperfusion in AMI ${ }^{43-46}$ Takahashi et al ${ }^{47}$ recently reported that PIA is associated with a greater degree of resolution of ST-segment elevation in patients with TIMI 3 flow after primary PCI. The relationship between PIA and resolution of ST-segment elevation or MBG remains to be further investigated. Fourth, PCI-induced distal embolism could have affected MBG after reperfusion. However, it is unlikely that the incidence of this type of embolism differed between patients with and without PIA. In addition, the use of distal protection devices also could affect MBG after reperfusion in AMI patients at high risk of clinically relevant embolization ${ }^{48}$ None of the present patients had these devices.

\section{Conclusions}

This study indicates that PIA is associated with MBG 2 or 3 after reperfusion in patients with first anterior wall AMI, suggesting that PIA has beneficial effects on myocardial tissue-level reperfusion.

\section{References}

1. Ottani F, Galvani M, Ferrini D, Sorbello F, Limonetti P, Pantoli D, et al. Prodromal angina limits infarct size: A role for ischemic preconditioning. Circulation 1995; 91: 291-297.

2. Nakagawa Y, Ito H, Kitakaze M, Kusuoka H, Hori M, Kuzuya T, et al. Effect of angina pectoris on myocardial protection in patients with reperfused anterior wall myocardial infarction: Retrospective clinical evidence of "preconditioning". J Am Coll Cardiol 1995; 25: $1076-$ 1083.

3. Anzai T, Yoshikawa T, Asakura Y, Abe S, Akaishi M, Mitamura H, et al. Preinfarction angina as a major predictor of left ventricular function and long-term prognosis after a first Q-wave myocardial infarction. J Am Coll Cardiol 1995; 26: 319-327.

4. Andreotti F, Pasceri V, Hackett DR, Davies GJ, Haider AW, Maseri A. Preinfarction angina as a predictor of more rapid coronary thrombolysis in patients with acute myocardial infarction. $N$ Engl J Med 1996; 334: 7-12.

5. Nagao K, Satou K, Arima K, Watanabe I, Yamashita M, Kanmatsuse K. Relationship between preinfarction angina and time interval to reperfusion with thrombolytic therapy in acute myocardial infarction. Jpn Circ J 1997; 61: 843-849.

6. Ishihara M, Sato H, Tateishi H, Kawagoe T, Shimatani Y, Kurisu S, et al. Implications of prodromal angina pectoris in anterior wall acute myocardial infarction: Acute angiographic findings and long-term prognosis. J Am Coll Cardiol 1997; 30: 970-975.

7. Solomon SD, Anavekar NS, Greaves S, Rouleau JL, Hennekens C, Pfeffer MA, for the HEART investigators. Angina pectoris prior to myocardial infarction protects against subsequent left ventricular remodeling. J Am Coll Cardiol 2004; 43: 1511-1514.

8. Van't Hof AWJ, Liem A, Suryapranata H, Hoorntje JCA, de Boer MJ, Zijlstra F, on behalf of the Zwolle Myocardial Infarction Study
Group. Angiographic assessment of myocardial reperfusion in patients treated with primary angioplasty for acute myocardial infarction: Myocardial blush grade. Circulation 1998; 97: 2302-2306.

9. Gibson CM, Cannon CP, Murphy SA, Ryan KA, Mesley R, Marble SJ, et al. Relationship of TIMI myocardial perfusion grade to mortality after administration of thrombolytic drugs. Circulation 2000; 101: $125-130$.

10. Henriques JPS, Zijlstra F, van't Hof AWJ, de Boer MJ, Dambrink JHE, Grosselink M, et al. Angiographic assessment of reperfusion in acute myocardial infarction by myocardial blush grade. Circulation 2003; 107: 2115-2119.

11. Hoffmann R, Haager P, Arning J, Christott P, Radke P, Blindt R, et al. Usefulness of myocardial blush grade early and late after primary coronary angioplasty for acute myocardial infarction in predicting left ventricular function. Am J Cardiol 2003; 92: 1015-1019.

12. The TIMI Study Group. The Thrombolysis In Myocardial Infarction (TIMI) trial. N Engl J Med 1985; 312: 932-936.

13. Rentrop KP, Cohen M, Blanke H, Phillips RA. Changes in collateral channel filling immediately after controlled coronary artery occlusion by an angioplasty balloon in human subjects. J Am Coll Cardiol 1985; 5: 587-592.

14. Kennedy JW, Trenholme SE, Kasser IS. Left ventricular volume and mass from single-plane cineangiocardiograms: A comparison of antero-posterior and right anterior oblique methods. Am Heart $J$ 1970; 80: 343-352.

15. Murry CE, Jennings RB, Reimer KA. Preconditioning with ischemia: A delay of lethal cell injury in ischemic myocardium. Circulation 1986; 74: $1124-1136$

16. Dayton C, Yamaguchi T, Warren A, Korthuis RJ. Ischemic preconditioning prevents postischemic arteriolar, capillary, and post capillary venular dysfunction: Signaling pathways mediating the adaptive metamorphosis to a protected phenotype in preconditioned endothelium. Microcirculation 2002; 9: 73-89.

17. Bolli R, Jeroudi MO, Patel BS, DuBose CM, Lai EK, Roberts R, et al. Direct evidence that oxygen-derived free radicals contribute to postischemic myocardial dysfunction in the intact dog. Proc Natl Acad Sci USA 1989; 86: 4695-4699.

18. DeFily DV, Chillian WM. Preconditioning protects coronary arteriolar endothelium from ischemia-reperfusion injury. Am J Physiol 1993; 265: H700-H706.

19. Davenpeck KL, Gauthier TW, Lefer AM. Inhibition of endothelialderived nitric oxide promotes P-selection expression and actions in the rat microcirculation. Gastroenterology 1994; 107: 1050-1058.

20. Engler RL, Schmid-Schonbein GW, Pavelec RS. Leukocyte capillary plugging in myocardial ischemia and reperfusion in the dog. Am J Pathol 1983; 111: 98-111.

21. Mazzoni M, Intaglietta M, Crogue Jr EJ, Arfors KE. Amiloridesensitive $\mathrm{Na}^{+}$pathways in capillary endothelial cell swelling during hemorrhagic shock. J Appl Physiol 1992; 73: 1467-1473.

22. Jerome SN, Akimitsu T, Korthuis RJ. Leukocyte adhesion, edema, and the development of postischmic capillary no-reflow. Am J Physiol 1994; 267: H1329-H1336.

23. Grisham MB, Granger DN, Lefer DJ. Modulation of leukocyte-endothelial interactions by reactive metabolites of oxygen and nitrogen: Relevant to ischemic heart disease. Free Radic Biol Med 1998; 25: $404-433$.

24. Watanabe N, Akasaka T, Toyota E, Fujimoto K, Kajita T, Shigeto F, et al. Three-dimensional microstructural abnormality of the coronary capillary network after myocardial reperfusion: Comparison between 'reflow' and 'no-reflow'. Circ J 2004; 68: 868-872.

25. Tailor A, Granger DN. Role of adhesion molecules in vascular regulation and damage. Curr Hypertens Rep 2000; 2: 78-83.

26. Korthuis RJ, Gute DC, Cepinskas G, Kvietys PR. Cellular mechanisms of acute vs delayed preconditioning. Pathophysiology 1998; 5: $35-48$

27. Richard V, Kaeffer N, Tron C, Thuillez C. Ischemic preconditioning protects against coronary endothelial dysfunction induced by ischemia and reperfusion. Circulation 1994; 89: 1254-1261.

28. Jerome SN, Akimutsu T, Gute DC, Korthuis RJ. Ischemic preconditioning attenuates capillary no-reflow induced by prolonged ischemia and reperfusion. Am J Physiol 1995; 268: H2063-H2067.

29. Bouchard JF, Lamontagne D. Mechanisms of protection afforded by preconditioning to endothelial function against ischemic injury. Am J Physiol 1996; 271: H1801-H1806.

30. Rubino A, Yellon DM. Ischaemic preconditioning of the vasculature: An overlooked phenomenon for protecting the heart? Trends Pharmacol Sci 2000; 21: 225-230.

31. Beauchamp P, Richard V, Tamion F, Lallemand F, Lebreton JP, Vaudry $\mathrm{H}$, et al. Protective effects of preconditioning in cultured rat endothelial cells: Effects on neutrophil adhesion and expression of 
ICAM-1 after anoxia and reoxygenation. Circulation 1999; 100: $541-546$

32. Laude K, Thuillez C, Richard V. Coronary endothelial dysfunction after ischemia and reperfusion: A new therapeutic target? Braz J Med Biol Res 2001; 34: $1-7$

33. Jacoby RM, Nesto RW. Acute myocardial infarction in the diabetic patients: Pathophysiology, clinical course and prognosis. J Am Coll Cardiol 1992; 20: 736-744.

34. Ishihara M, Sato H, Kawagoe T, Shimatani Y, Kurisu S, Nishioka K, et al. Impact of diabetes mellitus on long-term survival after acute myocardial infarction in patients with single vessel disease. Heart 2001; 86: 133-138.

35. Angeja BG, de Lemos J, Murphy SA, Marble SJ, Antman EM, Cannon CP, et al. Impact of diabetes mellitus on epicardial and microvascular flow after fibrinolytic therapy. Am Heart J 2002; 144: 649656.

36. Cohen RA. Dysfunction of vascular endothelium in diabetes mellitus. Circulation 1993; 87(Suppl 5): 67-76.

37. Tesfamariam B. Free radicals in diabetic endothelial cell dysfunction. Free Radic Biol Med 1994; 16: 383-391.

38. Nitenberg A, Valensi P, Sachs R, Dali M, Aptecar E, Attali JR. Impairment of coronary vascular reserve and ACh-induced coronary vasodilation in diabetic patients with angiographically normal coronary arteries and normal left ventricular systolic function. Diabetes 1993; 42: $1017-1025$.

39. Bucala R, Tracey KJ, Cerami A. Advanced glycosylation products quench nitric oxide and mediate defective endothelium-dependent vasodilation in experimental diabetes. J Clin Invest 1991; 87: 432 438.

40. Nasher PJ Jr, Brown RE, Oskarsson H, Winniford MD, Rossen JD.
Maximal coronary flow reserve and metabolic coronary vasodilation in patients with diabetes mellitus. Circulation 1995; 91: 635-640.

41. Zarich SW, Nesto RW. Diabetic cardiomyopathy. Am Heart J 1989; 118: $1000-1012$.

42. Gerich JE. Clinical significance, pathogenesis, and management of postprandial hyperglycemia. Arch Intern Med 2003; 163: 13061316.

43. Van't Hof AWJ, Liem A, de Boer M, Zijlstra F, for the Zwolle Myocardial Infarction Study Group. Clinical value of 12-lead electrocardiogram after successful reperfusion therapy for acute myocardial infarction. Lancet 1997; 350: 615-619.

44. Matetzky S, Freimark D, Chouraqui P, Novikov I, Agranat O, Rabinowitz B, et al. The distinction between coronary and myocardial reperfusion after thrombolytic therapy by clinical markers of reperfusion. J Am Coll Cardiol 1998; 32: 1326-1330.

45. Matetzky S, Novikov M, Gruberg L, Freimark D, Feinberg M, Elian $\mathrm{D}$, et al. The significance of persistent ST elevation versus early resolution of ST segment elevation after primary PTCA. J Am Coll Cardiol 1999; 34: $1932-1938$.

46. Johanson P, Jernberg T, Gunnarsson G, Lindahl B, Wallentin L, Dellborg M. Prognostic value of ST-segment resolution: When and what to measure. Eur Heart J 2003; 24: 337-345.

47. Takahashi T, Anzai T, Yoshikawa T, Maekawa Y, Asakura Y, Satoh $\mathrm{T}$, et al. Effect of preinfarction angina pectoris on ST-segment resolution after primary coronary angioplasty for acute myocardial infarction. Am J Cardiol 2002; 90: 465-469.

48. Limbruno U, de Caterina R. EMERALD, AIMI, and PROMISE: Is there still a potential for embolic protection in primary PCI? Eur Heart J 2006; 1-7. 